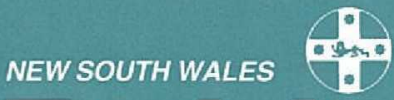 Public Health Bulletin
}

\section{CHILD ABUSE IN NSW}

Cait Lonie and David Lyle

Epidemiology and Health Services Evaluation Branch

Elisabeth Murphy and Peter Bayley

Services Development and Planning

NSW Health Department

\section{SUMMARY}

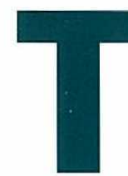

his article reports on a collaborative project between the NSW Health Department and the Department of Community Services (DCS) to examine DCS data on notifications of alleged and confirmed child abuse in NSW. The pattern of child abuse is described and recommendations are made to improve surveillance and child protection services.

\section{NOTIFICATION OF CHILD ABUSE CASES}

Notifications of suspected child abuse are made to the Department of Community Services, which is required to investigate the cases and take appropriate action under the Children (Care and Protection) Act 1987. If the alleged abuse is substantiated, then the case is confirmed. Cases that are confirmed or not confirmed may be closed or the case may be referred to other services for further counselling or support. Most clients who are confirmed as being abused are referred for further treatment.

\section{INCIDENCE OF REPORTED CHILD ABUSE}

For the period April 1992 to March 1993, 25,846 notifications of alleged child abuse were received by the DCS. As more than one notification can be made for a child, the notifications involved 21,009 children. Of the 25,846 notifications, 14,077 notifications of abuse were confirmed, involving 11,147 children.

\section{TYPE OF REPORTED CHILD ABUSE}

Four types of abuse are recognised: emotional, neglect, physical and sexual abuse. Frequencies of alleged and confirmed notifications are presented in Table 1 . Of the alleged abuse, about one quarter was due to each type. Of the confirmed notifications, 31 per cent of notifications were due to emotional abuse, 30 per cent sexual abuse and 24 per cent physical abuse. Fewer cases of neglect were confirmed.

\section{DEMOGRAPHIC CHARACTERISTICS}

\section{Age and sex}

Thirty-four per cent of the notifications were children aged less than five, 45 per cent were aged five to 12 years of age, and 17 per cent were aged 13 to 16 years. Children aged three years had the highest rate of alleged abuse (17.3/1,000), followed by those aged two $(16.8 / 1,000)$ and those aged less than one $(16.6 / 1,000)$.

A similar number of girls and boys aged less than 12 were reported to DCS, but girls over the age of 12 were twice as likely to be reported compared with boys of this age (Figure 1). Confirmed cases show a similar pattern. This results in a greater number overall of girls being reported ( 54 per cent of alleged cases and 56 per cent of confirmed cases).

\section{Contents}

\section{Articles}

95 Child abuse in NSW

98 Outbreak of Ross River virus disease in the South West Districts of NSW, summer 1993

100 Undertaking mass meningococcal vaccination: criteria and experiences

101 Possible case of human brucellosis

\section{Infectious Diseases}

102 Notifications

103 Death data

104 Tables

\section{Correspondence}

Please address all correspondence and potential contributions to:

The Editor,

NSW Public Health Bulletin,

Public Health Division,

NSW Health Department

Locked Bag No 961,

North Sydney NSW 2059

Telephone: (02) 3919218

Facsimile: (02) 3919232 


\section{TABLE 1}

TYPES OF ALLEGED AND CONFIRMED ABUSE

\begin{tabular}{|lrrrrrrrr|}
\hline Type of abuse & \multicolumn{3}{c}{ Alleged } & \multicolumn{4}{c|}{ Confirmed } \\
\hline & \multicolumn{2}{c}{ Notifications } & \multicolumn{2}{c|}{ Cases } & \multicolumn{2}{c|}{ Notifications } & \multicolumn{2}{c|}{ Cases } \\
& $N$ & $(\%)$ & $N$ & $(\%)$ & $N$ & $(\%)$ & $N$ & $(\%)$ \\
\hline Emotional & 6,881 & $(27)$ & 5,348 & $(26)$ & 4,321 & $(31)$ & 3,175 & $(29)$ \\
Neglect & 5,840 & $(23)$ & 4,578 & $(22)$ & 2,768 & $(18)$ & 2,029 & $(18)$ \\
Physical & 6,252 & $(24)$ & 5,044 & $(24)$ & 3,279 & $(24)$ & 2,635 & $(24)$ \\
Sexual & 6,792 & $(26)$ & 5,993 & $(29)$ & 3,696 & $(30)$ & 3,303 & $(30)$ \\
Unknown & 81 & $(0)$ & 46 & $(0)$ & 13 & $(0)$ & 5 & $(0)$ \\
\hline Total & 25,846 & $(100)$ & 21,009 & $(100)$ & 14,077 & $(100)$ & 11,147 & $(100)$ \\
\hline
\end{tabular}

\section{Child abuse in NSW}

\section{Continued from page 95}

Notification rates of sexual and physical abuse differed between girls and boys (Figure 2). More girls than boys were notified for sexual abuse at all ages, whereas physical abuse was reported more commonly for girls in the 13-16 age group.

\section{CULTURE}

Three quarters of the confirmed cases of abuse were of an English speaking background. Nine per cent of the cases were Aboriginal, and the abuse was more likely to have been emotional or neglect. The remaining confirmed cases were of non-English speaking backgrounds, and were more likely to have been physically abused.

\section{SOURCE OF NOTIFICATION}

One quarter of all reports came from relatives or neighbours. Other sources were parents ( 15 per cent), teachers (14 per cent), health services ( 13 per cent), and police/prison/court workers (12 per cent). Of the health sources, notifications were mostly made by Health Department social workers (22 per cent), Help Centres/ Care Team/ Sexual Assault Team (15 per cent), Health Department doctors (12 per cent), private doctors (12 per cent) and Health Department nurses (9 per cent).

The sources of referral that were most likely to have been confirmed were the child involved ( 73 per cent), police/prison or court workers (70 per cent) and Health Department sources (64 per cent). Those least likely to be confirmed were relatives and neighbours ( 40 per cent), other government departments (43 per cent) and parents (56 per cent).

\section{GEOGRAPHICAL DISTRIBUTION}

Notification rates of confirmed and non-confirmed child abuse in children aged less than 15 years by Health Areas and Regions' are presented in Figure 3. Cases were categorised into Areas and Regions using postcodes. Postcodes which crossed Area/Regional borders were placed into the Area or Region with the greatest proportion of population.

The localities with the highest notification rates were Orana and Far West Region (23.5/1,000), South West Region $(21.6 / 1,000)$ and the Illawarra Area $(20.4 / 1,000)$. However, the localities with the highest total number of cases were South Western Sydney (3,491 alleged cases), Western Sydney (3,130 alleged cases) and North Coast

\section{FIGURE 1}

NOTIFICATIONS OF ALLEGED CHILD ABUSE BY AGE AND SEX APRIL 1992-MARCH 1993

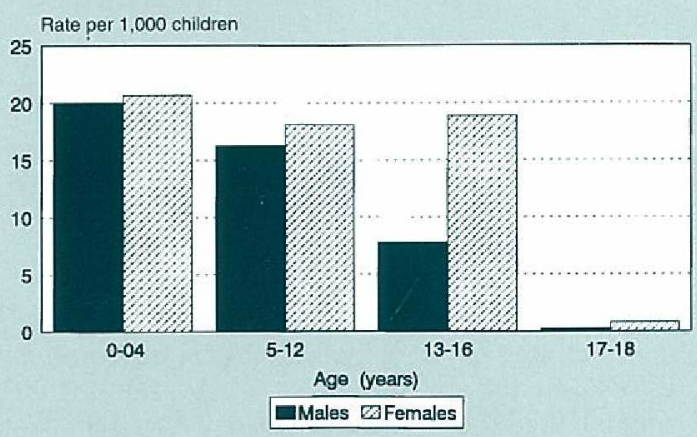

Source: Department of Community Services

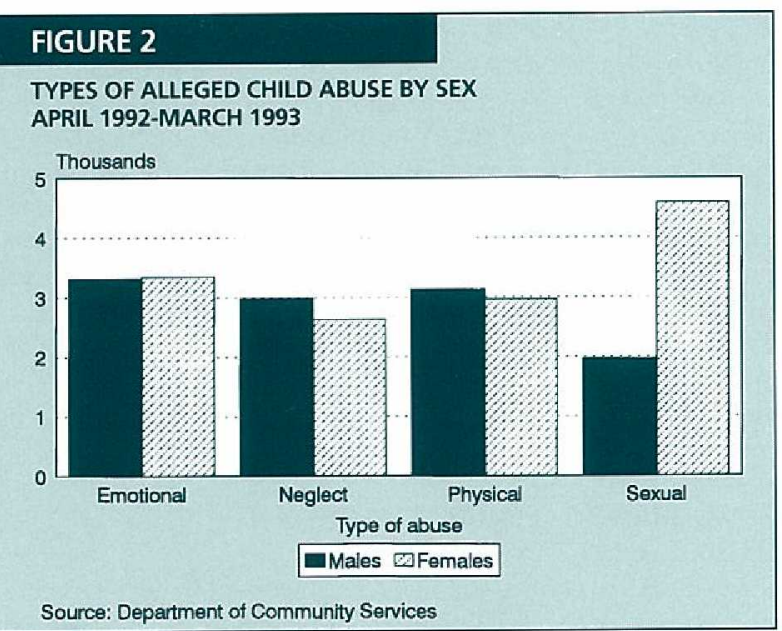

Region (2,007 alleged cases) (Figure 4). Areas with the greatest proportions of repeat notifications for that year were Illawarra ( 25 per cent), Central Sydney ( 24 per cent) and Western Sydney (23 per cent). The lowest proportions of repeat cases were in the New England (14 per cent) and North Coast Regions (14 per cent) and the Hunter Area (15 per cent).

\section{CONFIRMATION RATES}

Cases of alleged neglect were not confirmed as often as other types of abuse, with only 42 per cent of cases notified 

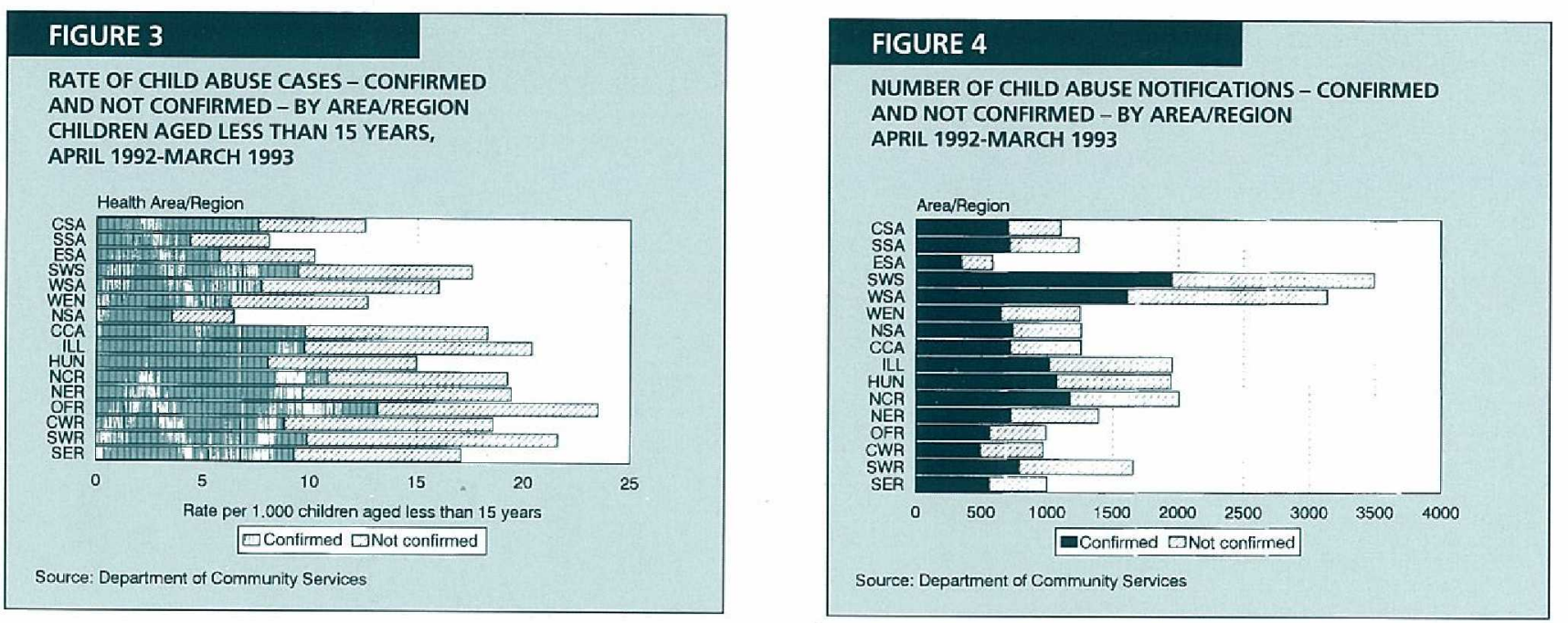

Abbreviations for Figures 3 and 4:

CSA = Central Sydney Area; ESA = Eastern Sydney Area; SSA = Southern Sydney Area; SWS = South-Western Sydney Area; WSA = Western Sydney Area; WEN = Wentworth Area; NSA = Northern Sydney Area; CCA = Central Coast Area; ILL = Illawarra Area; HUN = Hunter Area; NCR = North Coast Region; $\mathrm{NER}=$ New England Region; OFR = Orana and Far West Region; CWR = Central West Region; SWR = South West Region; SER = South East Region.

confirmed. More than 55 per cent of all the other types of alleged abuse were confirmed.

The Areas and Regions which have the highest confirmation rates are Central Sydney Area (63 per cent), Eastern Sydney Area ( 59 per cent), North Coast Region ( 58 per cent) and Northern Sydney Area (58 per cent). The Areas/Regions with the lowest rates were South West Region (47 per cent), Central Western Region (50 per cent) and Wentworth Area and New England Region (both 51 per cent).

\section{URGENCY RATING}

Notified cases are given an urgency rating from 1 to 3 . Cases rated as 1 require immediate assessment, 2 require assessment within two working days, and 3 require assessment within five working days. Overall, 25 per cent required immediate assessment, 25 per cent within two working days and 49 per cent within five working days.

South West Sydney had 1,076 cases rated as requiring immediate assessment, followed by Western Sydney (769) and Illawarra (509). South Western Sydney had 960 cases requiring assessment within two working days, followed by Western Sydney (822) and Illawarra (568).

Urgent cases requiring either immediate assessment or assessment within two days were most prevalent in Central Sydney (63 per cent of notified cases) and Eastern Sydney (59 per cent of notified cases).

Only 37 per cent of cases in New England Region and 39 per cent of cases in the Hunter Area were rated as urgent or requiring assessment within two working days.

\section{DISCUSSION}

These data have provided an estimate of the child abuse prevalence in NSW. Using this information and results from a survey of existing child protection services, the NSW Health Department has developed strategies to enhance child protection services. These are:

- enhancing service provision by defining the structure and function of existing child protection services;

\section{- a substantial financial commitment to the Areas and Districts to allow local development of coherent plans to improve co-ordination of services, particularly achievement of specified role levels; establishment of referral links between different levels of child protection services; and support of inter-agency collaboration and communication links, with a strong recommendation to Areas and District Health Services to develop and sustain similar links at a local level.}

It has been suggested that there may be an association between the availability of services and the numbers of notifications. We consider that the rates presented here are a reasonable indicator of the relative prevalence of abuse as they parallel the distribution of socio-demographic factors, and because most notifications come from sources other than health.

\section{RECOMMENDATIONS}

Child abuse has been included in the NSW Health Department's Injury Prevention Strategy since 1990. This is providing the first step towards an integrated approach to address the problem. To achieve targets for prevention, the NSW Health Department, in conjunction with the Area and District Health Services has plans to:

\section{- develop better surveillance systems which focus on outcomes; \\ - develop strategies to increase health professionals' awareness of the issues and encourage notifications of suspected cases; \\ - work with other sectors to address the issues; and develop and trial prevention strategies.}

\section{ACKNOWLEDGMENTS}

John Baker, Josie Hudson and Laurie Young

Department of Community Services

1. Data analysis was based on Regions prior to the establishment of Districts with rural restructuring. 